\title{
Pulmonary root translocation in malposition of great arteries repair allows right ventricular outflow tract growth
}

\author{
José Pedro da Silva, MD, ${ }^{\mathrm{a}}$ Luciana da Fonseca da Silva, MD, ${ }^{\mathrm{a}}$ Lilian Maria Lopes, MD, ${ }^{\mathrm{a}}$ \\ Luiz Felipe Moreira, MD, ${ }^{\mathrm{b}}$ Luiz Fernando Caneo, MD, ${ }^{\mathrm{b}}$ Sonia Meiken Franchi, MD, ${ }^{\mathrm{a}}$ \\ Alessandro Cavalcanti Lianza, MD, ${ }^{\mathrm{a}}$ José Francisco Baumgratz, MD, ${ }^{\mathrm{a}}$ and Jefferson Duarte Flavio \\ Magalhaes, $\mathrm{MD}^{\mathrm{c}}$
}

\begin{abstract}
Objective: Optimal surgical treatment of patients with transposition of the great arteries (TGA), ventricular septal defect (VSD), and pulmonary stenosis (PS) remains a matter of debate. This study evaluated the clinical outcome and right ventricle outflow tract performance in the long-term follow-up of patients subjected to pulmonary root translocation (PRT) as part of their surgical repair.
\end{abstract}

\begin{abstract}
Methods: From April 1994 to December 2010, we operated on 44 consecutive patients (median age, 11 months). All had malposition of the great arteries as follows: TGA with VSD and PS $(n=33)$; double-outlet right ventricle with subpulmonary VSD $(\mathrm{n}=7)$; double-outlet right ventricle with atrioventricular septal defect $(\mathrm{n}=1)$; and congenitally corrected TGA with VSD and PS $(n=3)$. The surgical technique consisted of PRT from the left ventricle to the right ventricle after construction of an intraventricular tunnel that diverted blood flow from the left ventricle to the aorta.
\end{abstract}

\begin{abstract}
Results: The mean follow-up time was $72 \pm 52.1$ months. There were $3(6.8 \%)$ early deaths and $1(2.3 \%)$ late death. Kaplan-Meier survival was $92.8 \%$ and reintervention-free survival was $82.9 \%$ at 12 years. Repeat echocardiographic data showed nonlinear growth of the pulmonary root and good performance of the valve at 10 years. Only 4 patients required reinterventions owing to right ventricular outflow tract problems.
\end{abstract}

Conclusions: PRT is a good surgical alternative for treatment of patients with TGA complexes, VSD, and PS, with acceptable operative risk, high long-term survivals, and few reinterventions. Most patients had adequate pulmonary root growth and performance. (J Thorac Cardiovasc Surg 2012;143:1292-8)

Transposition of the great arteries (TGA) with ventricular septal defect (VSD) and left ventricular outflow tract (LVOT) obstruction has a prevalence of $20 \%$ in the subgroup of neonates with TGA and associated VSD. ${ }^{1} \mathrm{Al}-$ though this heart malformation is relatively rare, there is much debate regarding the best procedure for its treatment. Since 1969, several surgical techniques have been developed and used for anatomic repair of this defect: the Rastelli operation, published in $1969^{2}$; the REV (réparation a l'étage ventriculaire) or Lecompte procedure $(1981)^{3}$; aortic translocation, first used by Nikaidoh ${ }^{4}$ (1984), who revived an idea proposed by Bex, Lecompte, and Baillot ${ }^{5}$ (1980) for TGA with intact ventricular septum; and the Metras procedure $^{6}$ (1997), which is a modification of the Lecompte operation. All of these techniques have some limitations,

\footnotetext{
From the Cardiovascular Surgery Division, ${ }^{\mathrm{a}}$ Beneficencia Portuguesa Hospital, São Paulo, Brazil; the Heart Institute, ${ }^{\mathrm{b}}$ University of São Paulo Medical School, São Paulo, Brazil; and the Pediatric Cardiology Department, ${ }^{\mathrm{c}}$ Rede Hospitais Perinatal, Rio de Janeiro, Brazil.

Disclosures: Authors have nothing to disclose with regard to commercial support.

Received for publication June 13, 2011; revisions received Oct 8, 2011; accepted for publication Nov 10, 2011; available ahead of print Dec 12, 2011.

Address for reprints: Jose Pedro da Silva, MD, Alameda dos Arapanes 631, ap 101, bl

3, São Paulo, SP 04524-001, Brazil (E-mail: dasilvajp@uol.com.br).

0022-5223/\$36.00

Copyright (C) 2012 by The American Association for Thoracic Surgery doi:10.1016/j.jtcvs.2011.11.027
}

mainly related to patch augmentation or conduit insertion in the right ventricular outflow tract (RVOT).

With the aim of overcoming these limitations and assuring pulmonary valve competency, since April 1994 we have used pulmonary root translocation (PRT) as an alternative surgical approach for TGA with VSD and pulmonary stenosis (PS) and for selected cases of double-outlet right ventricle with subpulmonary VSD. ${ }^{7}$ More recently, we extended its use as part of the double switch procedure in patients with congenitally corrected TGA, PS, and VSD. ${ }^{8}$

The objective of this study was to evaluate the clinical outcome and the RVOT performance in the long-term follow-up of patients after PRT.

\section{PATIENTS AND METHODS Patients}

We reviewed the prospectively collected clinical and echocardiographic data of 44 consecutive pediatric patients who underwent PRT as part of a procedure to repair their complex congenital heart disease from April 1994 to December 2010. The included patients had malposition of the great arteries as follows: TGA with VSD and PS $(\mathrm{n}=33)$; double-outlet right ventricle with subpulmonary VSD $(n=7)$; double-outlet right ventricle with atrioventricular septal defect $(n=1)$; and congenitally corrected TGA with VSD and PS $(\mathrm{n}=3)$. The mean patient age was $24 \pm 36$ months, with a median age of 11 months (range, 1 month to 11 years). Twenty-eight patients were male and 16 were female. Ten $(13.6 \%)$ patients had previous surgical procedures: systemic-pulmonary shunt had been performed in 

Abbreviations and Acronyms
LVOT $=$ left ventricular outflow tract
PRT = pulmonary root translocation
PS = pulmonary stenosis
$\mathrm{REV}=$ réparation a l'étage ventriculaire
$\mathrm{RVOT}=$ right ventricular outflow tract
$\mathrm{TGA}=$ transposition of the great arteries
VSD = ventricular septal defect

6 patients and pulmonary banding in 4 patients. This study was approved by the Ethics Committee at the Hospital Beneficencia Portuguesa de São Paulo (CAE-0023.0.360.000-07), and informed consent was obtained from the patients' parents.

\section{Surgical Technique}

$\mathrm{We}^{8}$ previously reported the surgical details of PRT for different anatomic variations of TGA. Figure 1 depicts the main steps for repairing TGA, VSD, and PS. The intact pulmonary root with valve was translocated to the left side of the aorta for connection to the right ventricle without a Lecompte maneuver. The VSD was routinely enlarged by resection of the conal septum except in 6 patients with a large VSD extending to the conal septum. Commissurotomy and probe dilation of the pulmonary valve was used in borderline-sized pulmonary valves that we judged not to require patch enlargement. At least $40 \%$ of the pulmonary root circumference was sutured directly to the right ventricular wall. In 3 patients with a diagnosis of congenitally corrected TGA with VSD and PS, the Senning procedure, atrial switch repair, was added on.

Regarding the enlargement of the pulmonary root, we adopted a strategy that was similar to that described for the repair of tetralogy of Fallot. ${ }^{9}$ We enlarged the pulmonary annulus when the pulmonary annulus Z-score was less than -3 , performing the intraoperative measurement with a Hegar dilator, or, when the postrepair systolic gradient exceeded $35 \mathrm{~mm} \mathrm{Hg}$, using catheter measurements after cardiopulmonary bypass. In the latter situation, we put the patient back on the pump, removed 1 or 2 interrupted sutures, opened the pulmonary root at the commissural site, and performed a small enlargement with a bovine pericardial valved patch.

\section{Echocardiographic Studies}

Each patient was subjected to an echocardiographic study protocol consisting of a preoperative study, an early postoperative study, and follow-up studies scheduled either annually or according to the patient's needs. The diameters of the aortic, pulmonary, tricuspid, and mitral annuli were measured, as was the peak velocity of the right and left ventricular outlets. The degree of pulmonary insufficiency and right ventricular function were determined qualitatively by the pediatric echocardiographer. The diameter measurements were expressed in millimeters. The left ventricular function was evaluated using ejection fraction calculated by the Teicholz method. Insufficiency of the pulmonary and aortic valves was scored as absent, mild, moderate, or severe. The RVOT and LVOT were evaluated by measuring the peak pressure gradients across the pulmonary and aortic valves.

\section{Clinical Follow-up}

The patients were followed up after the operation, and the patient's local physician was contacted in case of death. A final follow-up of all patients was conducted from January to March 2011 by telephone or by outpatient evaluation. The functional status according to the New York Heart Association class and the use of medicines to treat heart failure and/or arrhythmias were recorded.

\section{Data Analysis}

Descriptive data for continuous variables are presented as mean \pm standard deviation or as median with range; categorical variables are presented as relative frequencies. The outcome variables were defined as time from the PRT procedure to events (death, reoperation for RVOT obstruction, LVOT obstruction, residual VSD, or pulmonary balloon dilatation procedure) and recent clinical status. The probability of survival and event-free survival was estimated according to the Kaplan-Meier method and included hospital mortality. Pulmonary valve diameter and gradient changes over time were analyzed using longitudinal data analysis. The exact time of the assessment and all available data were used in these analyses. The $\chi^{2}$ method was applied to compare categorical variables. Analyses were performed using SPSS software version 17.0 (SPSS, Inc, Chicago, Ill)

\section{RESULTS}

There were $3(6.8 \%)$ hospital deaths. The first patient was an 8 -year-old boy with a long history of cyanosis who died of heart failure, and the second patient was a 6-month-old boy who had a good hemodynamic result after the operation but died of gram-negative sepsis. The third patient was a 36-day-old baby who underwent surgery 1 day after being intubated and transfused owing to severe hypoxemia. He could not be weaned from cardiopulmonary bypass and died of multiple organ failure despite the use of cardiopulmonary support with extracorporeal membrane oxygenation for 3 days. All 3 deaths occurred in patients with TGA, VSD, and PS who were operated on between 1994 and 2005. There were no hospital deaths or late deaths in the 26 subsequent patients.

The mean aortic crossclamp time was $140 \pm 34$ minutes, and the mean cardiopulmonary bypass time was $195 \pm 42$ minutes. The median stay in the intensive care unit was 13 days (range, 2-61 days), and the median hospital stay was 24 days (range, 12-115 days). Atrioventricular block occurred in 2 patients, necessitating permanent pacing.

\section{Longitudinal Clinical Outcome}

Long-term follow-up information was obtained for all patients. The mean follow-up time was $72 \pm 52.1$ months. The survival and reintervention-free survival curves, which include the hospital deaths, showed a $92.8 \% \pm 3.8 \%$ survival at $1,5,10$, and 12 years of follow-up, an $88 \% \pm$ $4.9 \%$ reintervention-free survival at 1 year, and an $82.9 \%$ $\pm 5.9 \%$ survival at 2, 5, 10, and 12 years of follow-up (Figure 2). One patient who had progressive postoperative RVOT obstruction died suddenly 72 days after the operation. The follow-up showed that 7 patients needed a total of 8 reinterventions after the PRT. These reinterventions were required owing to residual VSD in 2 patients, LVOT obstruction (left ventricular-aortic tunnel stenosis) in 1 patient, RVOT aneurysm in 2 patients ( 1 owing to endocarditis and 1 owing to in situ pericardial flap dilation), and RVOT obstruction (pulmonary stenosis) in 2 patients. The reoperations for residual VSD closure and resection of muscular obstruction in the LVOT occurred in the initial 6 months 

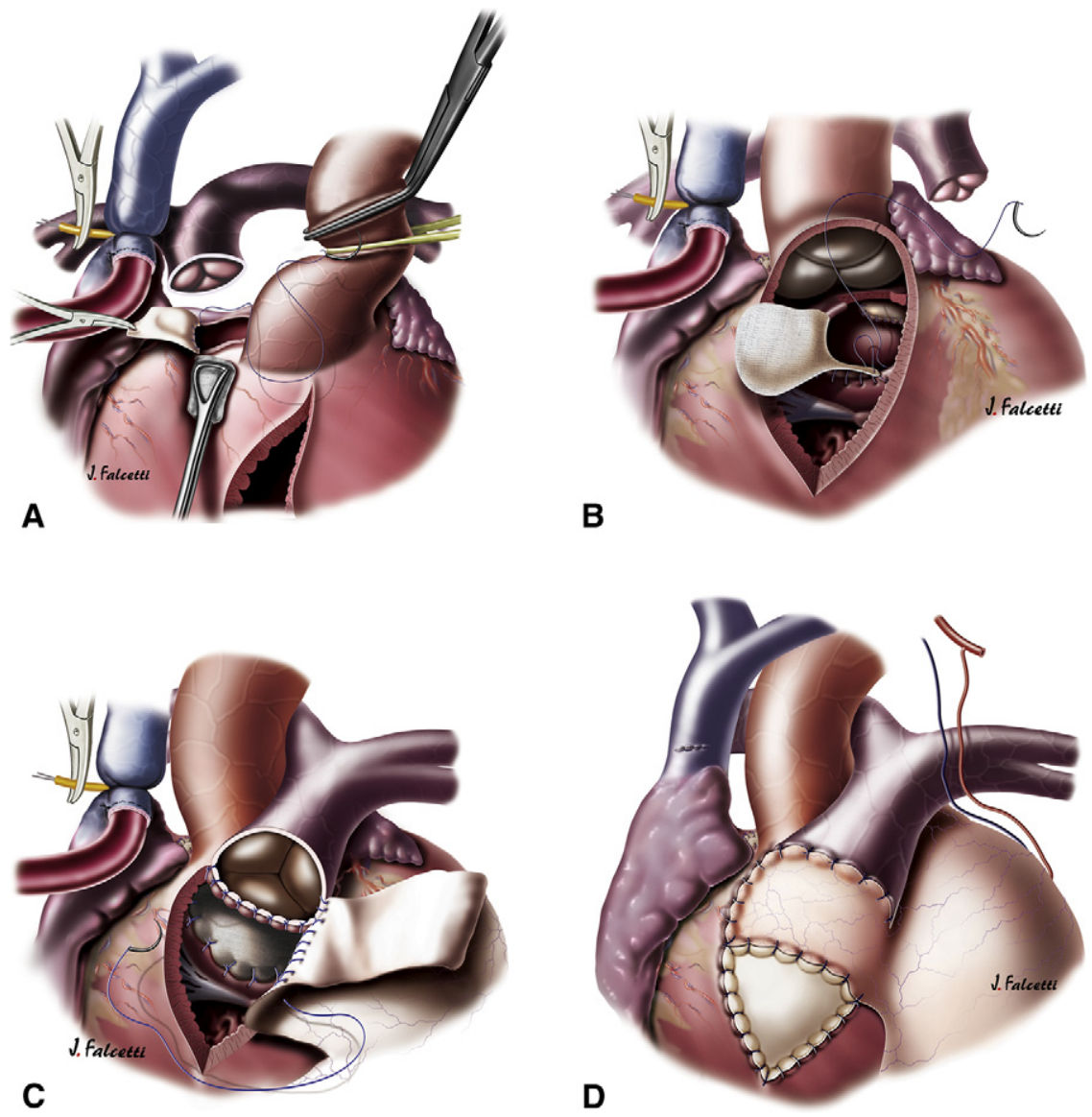

FIGURE 1. A, The pulmonary root is dissected out and its origin is closed using a glutaraldehyde-treated autologous pericardial patch. B, After partial resection of the conal septum, a Dacron patch is used to create a tunnel from the left ventricle to the aorta. $\mathrm{C}$, The pulmonary root is sutured to the right ventriculotomy with a running 6-0 polydioxanone suture, and the right ventricular outflow tract is completed using an in situ pericardial patch combined with a glutaraldehyde-treated autologous pericardial patch. D, The final appearance after the procedure.

of follow-up. RVOT aneurysm repair was performed 16.3 months after the initial operation. The 2 patients with RVOT obstruction were treated with percutaneous balloon dilation of the pulmonary valve, 1 of them 2 years after PRT, with reduction of the transpulmonary gradient from 55 to $30 \mathrm{~mm} \mathrm{Hg}$ and an excellent outcome thereafter. The second patient underwent this procedure 13 years after PRT, reducing the right ventricular-pulmonary arterial gradient from 95 to $70 \mathrm{~mm} \mathrm{Hg}$. A surgical approach was recommended, but the patient and her family declined surgery because she was asymptomatic. The patient who had endocarditis underwent homograft replacement of the pulmonary valve and, 5 years later, implantation of a pericardial valve prosthesis. All 40 survivors are currently asymptomatic with good biventricular function.

\section{Longitudinal Assessment of Pulmonary Valve Growth and the Ventricular-Pulmonary Arterial Peak Pressure Gradient}

The pulmonary valve diameter data and the ventricularpulmonary arterial pressure gradient data, obtained from 1 preoperative and multiple postoperative echocardiograms in 38 patients with more than 1 year of follow-up, are shown in Figure 3, $A$ and $B$, respectively. There was a median of 5 (range, 2-7) measurements per patient. The data collected subsequent to reinterventions were not included for the 3 patients who underwent pulmonary valve balloon dilation $(\mathrm{n}=2)$ or replacement $(\mathrm{n}=1)$.

Nonlinear growth of the pulmonary valve diameter occurred over time, as shown in Figure 3. Concerning the RVOT pressure gradient variations, there was an overall tendency of progressive decrease, and at the end of the curve, most patients had gradients less than $25 \mathrm{~mm} \mathrm{Hg}$.

Pulmonary annulus enlargement, which was performed in 15 of the 44 patients, changed the pulmonary root growth pattern and affected pressure gradient variation (Figure 4) compared with the group of patients who did not have pulmonary root enlargement (Figure 3). The nonenlarged group had a more favorable growth pattern as reflected by a continuous increase in pulmonary root growth. The postoperative pressure gradient across the pulmonary valve was lower in the root enlargement group in the immediate 


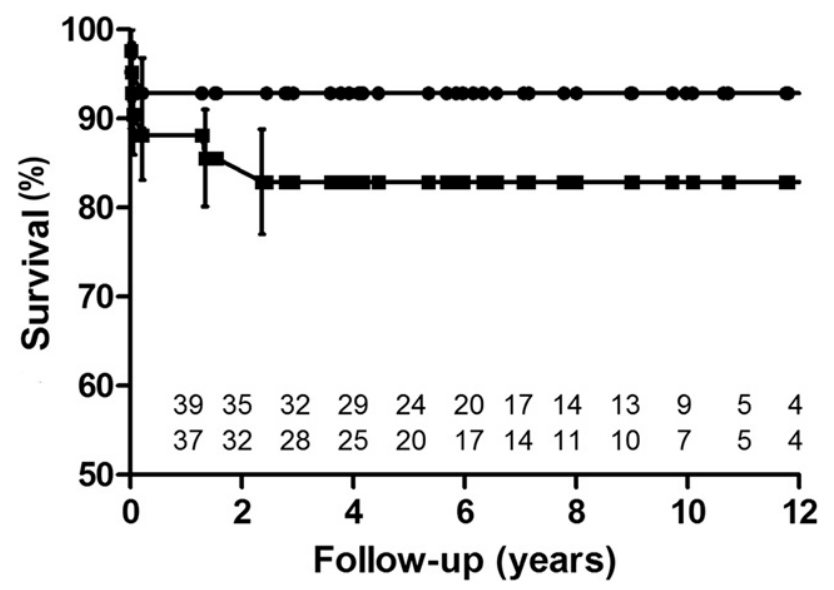

FIGURE 2. Kaplan-Meier estimates of survival (circles) and reintervention-free survival (squares) for 44 patients after pulmonary root translocation as part of repair of transposition of the great arteries.

postoperative period, but it did not decrease with time. This was consistent with the lower rate of pulmonary annulus growth in the echocardiographic follow-up period. Figure 5 shows RVOT images from serial echocardiograms of a 5-year-old girl subjected to PRT who had excellent anatomic and functional results.

A cross-sectional analysis of the most recent echocardiographic data of 38 survivors with more than 1 year of follow-up showed that all had normal left ventricular ejection fraction values. Moderate or severe pulmonary valve insufficiency was observed in 4 patients, $1(4.16 \%)$ in the nonenlarged group and $3(21.45 \%)$ in the enlarged group; the difference was not statistically significant $(P=.09)$.

\section{DISCUSSION}

In this study, PRT was used for the anatomic repair of TGA with VSD and PS and other selected types of malposition of the great arteries. This technique was used with the intention of maintaining pulmonary valve function, including the capacity for growth, while avoiding the problems that are usually inherent in a right ventricular- pulmonary arterial conduit. Furthermore, by avoiding incising or mobilizing the aorta, we preserved aortic valve anatomy and function.

The Lecompte maneuver is not useful in this operation, which leaves the aorta in its native position, because the aorta is already in a very anterior position in patients with TGA. After the Lecompte maneuver, the translocated pulmonary trunk would be very close to the sternum, increasing the risk of bleeding during a reintervention. Conversely, the elongation of the pulmonary artery owing to retention of its root allows anastomosis of the pulmonary artery to the right ventricle to be performed without tension. An autologous pericardial flap was used to complete the RVOT reconstruction, optimizing its potential for growth. This pericardial flap was limited to the anterior aspect of the pulmonary root, and a piece of glutaraldehyde-treated autologous pericardium was added to complete the RVOT reconstruction. We used this composite patch technique rather than using a single flap of in situ pericardium in an effort to prevent aneurysmal dilation of the pericardial hood, which occurred in 1 case in this series.

When enlargement of the pulmonary root circumference was needed, we augmented it with a small monocusp bovine pericardial patch, ${ }^{8}$ the size of which was just sufficient for preventing an elevated right ventricular-pulmonary root pressure gradient. We hope that as the patient's own valve grows, using the smallest possible artificial patch will result in less pulmonary valve regurgitation. We found that pulmonary valve growth was less adequate in patients who underwent patch enlargement of the pulmonary root than in patients without enlargement. This was associated with a greater incidence (statistical tendency) of pulmonary regurgitation in those patients, indicating that it is important to preserve the pulmonary valve without enlargement. One possible explanation for the observed decrease in pulmonary growth in patients undergoing patch enlargement is that there could have been a reaction to the implanted xenograft material. The bovine pericardial patch may cause inflammation and fibrosis in the native valve, impeding its growth. Valve patches made of a different material, such
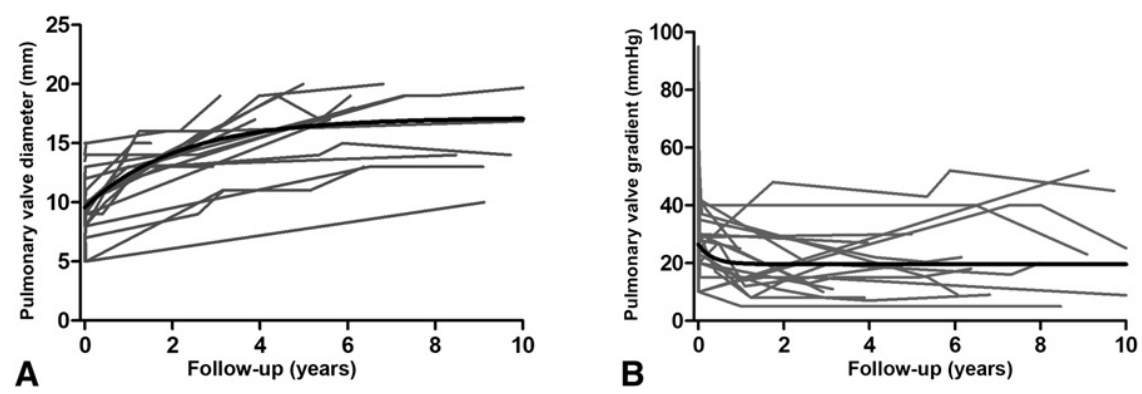

FIGURE 3. Data from repeated postoperative echocardiograms performed in 20 patients with more than 1 year of follow-up after pulmonary root translocation without patch enlargement. The data show changes over time in pulmonary valve diameter (A) and in the pressure gradient across the pulmonary valve (B). Each line represents data from individual patients, and the bold line represents the average time trend for the longitudinal data model. 

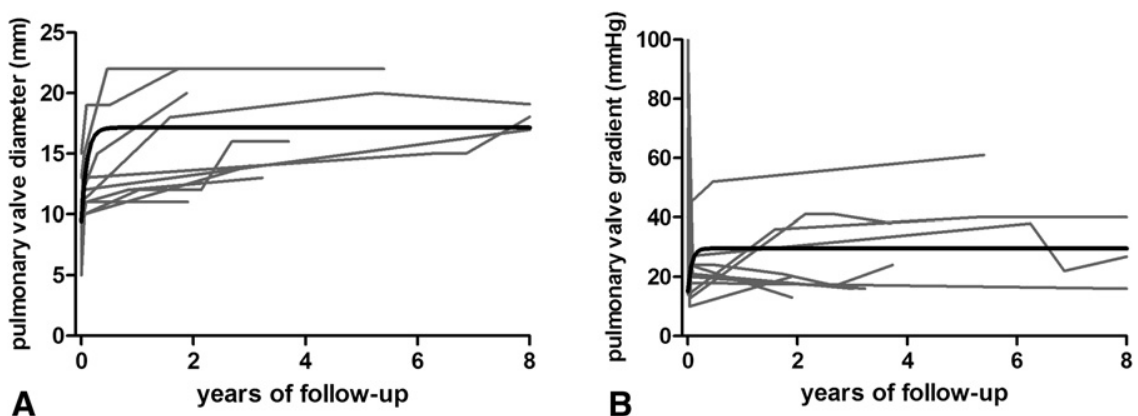

FIGURE 4. Data from preoperative and repeated postoperative echocardiograms performed in 10 patients with more than 1 year of follow-up after pulmonary root translocation with patch enlargement. The data show changes over time in pulmonary valve diameter (A) and pressure gradients across the pulmonary valve (B). Each curve represents data from individual patients, and the bold curve represents the average time trend for the longitudinal data model.

as polytetrafluoroethylene, ${ }^{10-12}$ or use of a homologous decellularized pulmonary valve cusp ${ }^{13}$ may further improve long-term valve performance.

The observed hospital mortality, $6.8 \%$, is acceptable. Notably, there were 3 hospital deaths in the initial group of 18 patients of this series, but no deaths in the 26 subsequent patients. Thus, the PRT procedure can probably be performed with a lower mortality rate inasmuch as the higher initial mortality rate was most likely related to the learning curve for the procedure.

The actuarial survival curve after PRT shows $92.8 \%$ survival at 10 years, which is quite good compared with the outcomes of large series of patients who underwent the Rastelli and REV operations. ${ }^{14-16}$ The $82.9 \%$ reinterventionfree survival in our series at a mean follow-up of 10 years is also encouraging. In fact, only 4 patients $(10 \%$ of the 40 survivors) underwent RVOT reinterventions.

Obstruction of the LVOT, which can be a complication after left ventricular-aortic tunnel construction, occurred in a small number of patients in our series. However, it is too early to predict its real incidence, because it may be related to patient growth, which is still ongoing in this series of pediatric patients.

Left ventricular function of all patients was good according to the data analysis of most recent echocardiographic studies. Although good left ventricular function is expected after any procedure that results in anatomic repair of TGA (ie, the left ventricle as the systemic ventricle), this has not always been the case in previous studies. Graham and coworkers ${ }^{17}$ found dysfunction and residual left ventricular dilation and wall hypertrophy in 8 of 11 patients after successful Rastelli operations in patients with TGA, VSD, and LVOT obstruction. In addition, Kreutzer and colleagues ${ }^{14}$ reported that left ventricular dysfunction and sudden death were important causes of late death in their series, contributing to unsatisfactory survivals. According to their report, contractile dysfunction was explained by hypoxia, obstruction, and volume overloading over a prolonged period. Good long-term left ventricular function in our series of patients was probably related not to the operative technique but rather to the relatively young age of the patients. This is in accordance with the findings of Hörer and associates, ${ }^{18}$ who reported that age greater than 4 years at the time of surgery is an important factor in the development of postoperative cardiomyopathy. However, their study also showed that all patients under 4 years of age required conduit reintervention after 12 years of follow-up. PRT is advantageous in terms of early operation to prevent left ventricular dysfunction because it can be performed on younger patients inasmuch as it
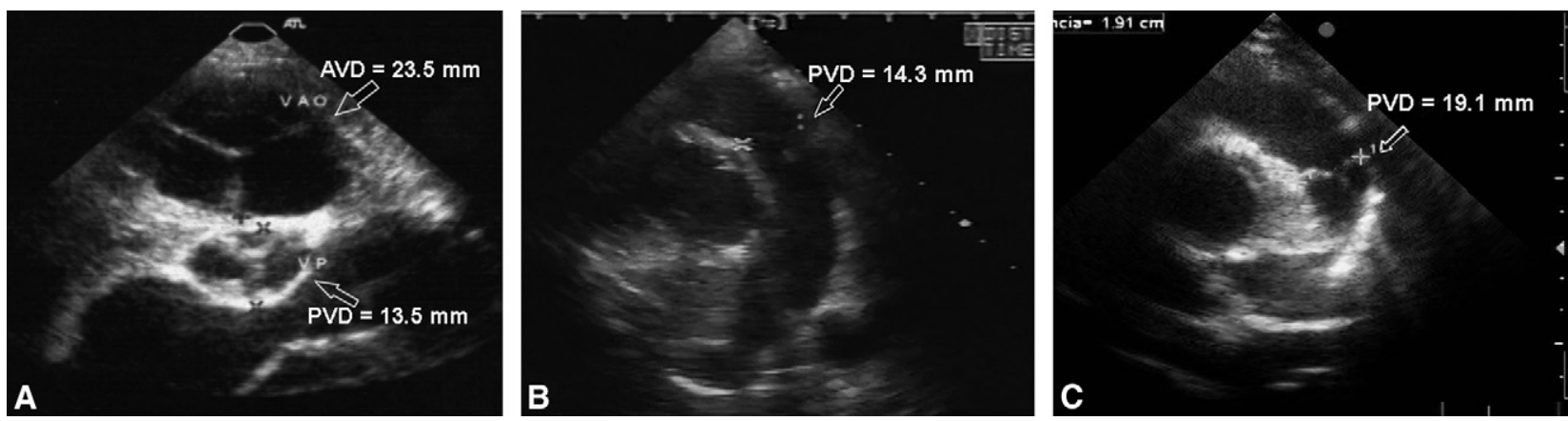

FIGURE 5. Echocardiographic images from a girl who underwent pulmonary root translocation surgery at 5 years of age: preoperative cross-sectional view of the aortic and pulmonary valves on the day of the surgery (A), and postoperative views of the translocated pulmonary valve after 3 years (B) and 8.5 years (C) of follow-up. $A V D$, Aortic valve diameter; $P V D$, pulmonary valve diameter; $A O$, aorta. 
preserves the growth potential of the translocated pulmonary root.

The Nikaidoh operation (aortic translocation) has as its main advantage better alignment of the left ventricle and the aorta. ${ }^{4}$ The importance of alignment came to light because of concerns about LVOT obstruction after the Rastelli procedure, ${ }^{14,15}$ prompting surgeons to adopt the Nikaidoh operation. ${ }^{19,20}$ However, better alignment is achieved by surgical handling of the aortic root and the coronary arteries, which can result in aortic valve insufficiency and in myocardial ischemia. These concerns, mainly aortic regurgitation, have already shown up in midterm followup reports of 1 series in which 3 of 11 patients experienced moderate aortic insufficiency ${ }^{20}$ and in another series that found that 8 of 18 survivors experienced mild aortic regurgitation. ${ }^{21}$ Notably, the Nikaidoh operation sacrifices the pulmonary valve; therefore, single or multiple reoperations are expected to be required using the currently available pulmonary prostheses.

Lecompte and colleagues ${ }^{3}$ addressed problems of LVOT obstruction related to the classic Rastelli operation by radical conal septum resection, resulting in a wider left ventricular-aortic tunnel and decreasing the risk of subaortic stenosis. That group also introduced the Lecompte maneuver, which involves the anterior mobilization of the pulmonary trunk to permit direct connection between the pulmonary artery and the right ventricle. This maneuver is accomplished by transection of the ascending aorta, and a monocusp valve is placed to complete the RVOT. This important contribution, also named the REV procedure, improved the concepts of left ventricular-aortic tunnel construction and eliminated the need for a right ventricular-pulmonary arterial conduit. It could be performed in younger patients and promised fewer reoperations than the Rastelli procedure. Di Carlo and coworkers ${ }^{16}$ recently published results for the REV procedure in the largest reported series to date. They analyzed $181(88 \%)$ hospital survivors of 205 patients who were operated on from 1980 to 2003. The rates of overall survival and freedom from any reoperation at 25 years were $85 \%$ and $45 \%$, respectively. The most frequent reason for reoperation was recurrent RVOT obstruction (36 patients) and rarely was LVOT obstruction (just 3 patients). Although these results show improvement over those of the Rastelli operation, the REV procedure is not an optimal solution for RVOT problems. The main theoretical advantage of PRT over the REV procedure is that it results in pulmonary valves with better functional status.

In the Metras operation, ${ }^{6}$ an aortic autograft cylinder that is taken from the ascending aorta is used to extend the length of the pulmonary trunk. This pulmonary artery extension allows it to be brought to the aorta's left side for direct right ventricular connection without use of the Lecompte maneuver. However, the solution for pulmonary valve insufficiency relies on a monocusp valve insertion, which we consider less efficient for preserving pulmonary valve function than the PRT method.

More recently, $\mathrm{Hu}$ and coworkers ${ }^{22}$ reported double root translocation of the great vessels for TGA with PS. This procedure is attractive because it combines the goals of left ventricular-aortic alignment and pulmonary valve preservation. However, it is more complex than PRT, and the aortic crossclamp time is much longer. ${ }^{23}$ That procedure also requires aortic transection and, as in the Nikaidoh operation, risks the integrity and function of the aortic valve and coronary arteries. In our opinion, the technique needs further evaluation but may be advantageous in a subgroup of patients with the same diagnosis as in our series who have small or noncommitted VSDs.

A substantial percentage of our patients in the group of TGA, VSD, and PS, despite having a preoperative left ventricular-pulmonary arterial gradient higher than $70 \mathrm{~mm} \mathrm{Hg}$, had a near normal pulmonary valve once explanted and freed from the subvalvular muscular and fibrous tissues. This raises the question as to whether subpulmonary conal resection and an arterial switch operation may have been a better option for these patients. ${ }^{24}$ However, the guidelines for selection of the best anatomic LVOT obstruction type for this surgical option have not been established. Because of our good results using PRT in this subgroup of patients, we prefer to keep the normal aortic valve in the systemic circulation while waiting for consistent data to be published regarding this interesting option.

PRT is a relatively simple surgical technique that maintains the growth potential of the pulmonary root and keeps the aorta untouched in its original position. It is notable that most of our older patients (with more than 5 years of followup) had good anatomic and functional RVOT performance at their most recent echocardiography studies, suggesting that PRT may offer permanent resolution for these complex congenital heart defects in a reasonable proportion of patients.

PRT has technical limitations in a subgroup of patients with the same diagnosis as in our series who have small or noncommitted VSDs or small or heavily trabeculated right ventricles. These conditions present difficulties for left ventricular-aortic tunnel construction. Pulmonary atresia or very small and dysplastic pulmonary valves are obvious contraindications for this technique. In the former situation, the Nikaidoh, the $\mathrm{Hu}$, or single-ventricle physiology procedures are the recommended repair options. In the latter situation, the Rastelli or the Lecompte procedures can be used.

\section{Study Limitations}

This study was limited in that the results could not be compared with a matched control group. In addition, an objective results comparison with the related publications was 
difficult owing to dissimilarities in institutional and patient characteristics as well as to period differences for the case series. The literature data were used as a "control" mainly to discuss the possible clinical implications of differences in surgical techniques.

\section{CONCLUSIONS}

PRT is a good surgical alternative for treatment of patients with TGA complexes associated with VSD and PS. The operative risk was acceptable, and the patients had a high long-term survival. Few reinterventions were needed, and the great majority of patients had adequate pulmonary root growth and performance.

We are grateful to Rodolfo A. Neirotti, $\mathrm{MD}, \mathrm{PhD}$, for his expertise, valuable suggestions, and help with the review of this paper. We also acknowledge the assistance of Ms Leticia Tavares da Silva, who helped us communicate with the patients' families and with data collection.

\section{References}

1. Kirklin JW, Blackstone EH, Tchervenkov CI, Castaneda AR. Clinical outcomes after the arterial switch operation for transposition. Patient, support, procedural and institutional risk factors. Congenital Heart Surgeons Society. Circulation. 1992;86:1501-15.

2. Rastelli GC. A new approach to the "anatomic" repair of transposition of the great arteries. Mayo Clin Proc. 1969;44:1-12.

3. Lecompte Y, Zannini L, Hazan E, Jarreau MM, Bex JP, Tu TV, et al. Anatomic correction of transposition of the great arteries. J Thorac Cardiovasc Surg. 1981; 82:629-31.

4. Nikaidoh H. Aortic translocation and biventricular outflow tract reconstruction: a new surgical repair for transposition of the great arteries associated with ventricular septal defect and pulmonary stenosis. J Thorac Cardiovasc Surg. 1984; 88:365-72.

5. Bex JP, Lecompte Y, Baillot F, Hazan E. Anatomical correction of transposition of the great arteries. Ann Thorac Surg. 1980;29:86-8.

6. Metras D, Kreitmann B, Riberi A, Yao JG, el-Khoury E, Wernert F, et al. Extending the concept of the autograft for complete repair of transposition of the great arteries with ventricular septal defect and left ventricular outflow tract obstruction: a report of ten cases of a modified procedure. J Thorac Cardiovasc Surg. 1997; 114:746-54.

7. da Silva JP, Baumgratz JF, da Fonseca L. Pulmonary root translocation in transposition of great arteries repair. Ann Thorac Surg. 2000;69:643-5.

8. da Silva JP, da Fonseca L. Pulmonary root translocation. Oper Tech Thorac Cardiovasc Surg. 2009;14:23-34.
9. Kouchoukos NT, Blackstone EH, Doty DB, Hanley FL, Karp RB. Ventricular septal defect with pulmonary stenosis or atresia. In: Kouchoukos NT, Blackstone EH, Doty DB, Hanley FL, Karp RB, eds. Kirklin/Barratt-Boyes cardiac surgery: morphology, diagnostic criteria, natural history, techniques, results and indications, Volume 1, 3rd ed. Philadelphia: Elsevier Science; 2003. p. 946-1073.

10. Yamagishi M, Kurosawa H. Outflow reconstruction of tetralogy of Fallot using a Gore-Tex valve. Ann Thorac Surg. 1993;56:1414-7.

11. Oku H, Matsumoto T, Kitayama H, Ueda M, Saga T, Shirotani H. Semilunar valve replacement with a cylindrical valve. J Card Surg. 1993;8:666-70.

12. Turrentine MW, McCarthy RP, Vijay P, McConnell KW, Brown JW. PTFE monocusp valve reconstruction of the right ventricular outflow tract. Ann Thorac Surg. 2002;73:871-80.

13. Cowgill LD, Campbell DN, Kelminson L, Clarke DR. Repair of pulmonary valve insufficiency using an autologous monocusp. Ann Thorac Surg. 1986;42: 587-9.

14. Kreutzer C, De Vive J, Oppido G, Kreutzer J, Gauvreau K, Freed M, et al. Twenty-five-year experience with Rastelli repair for transposition of the great arteries. J Thorac Cardiovasc Surg. 2000;120:211-23.

15. Dearani JA, Danielson GK, Puga FJ, Mair DD, Schleck CD. Late results of the Rastelli operation for transposition of the great arteries. Semin Thorac Cardiovasc Surg Pediatr Card Surg Annu. 2001;4:3-15.

16. Di Carlo D, Tomasco B, Cohen L, Vouhé P, Lecompte Y. Long-term results of the REV (réparation à l'ètage ventriculaire) operation. J Thorac Cardiovasc Surg. 2011;142:336-43.

17. Graham TP Jr, Franklin RC, Wyse RK, Gooch V, Deanfield JE. Left ventricular wall stress and contractile function in transposition of the great arteries after the Rastelli operation. J Thorac Cardiovasc Surg. 1987;93:775-84.

18. Horer J, Schreiber C, Dworak E, Cleuziou J, Prodan Z, Vogt M, et al. Long-term results after the Rastelli repair for transposition of the great arteries. Ann Thorac Surg. 2007;83:2169-75.

19. Bautista-Hernandez V, Marx GR, Bacha EA, del Nido PJ. Aortic root translocation plus arterial switch for transposition of the great arteries with left ventricular outflow tract obstruction: intermediate-term results. J Am Coll Cardiol. 2007;49: 485-90

20. Morell VO, Jacobs JP, Quintessenza JA. The role of aortic translocation in the management of complex transposition of the great arteries. Semin Thorac Cardiovasc Surg. Pediatr Card Surg Annu. 2004;7:80-4.

21. Yeh T Jr, Ramaciotti C, Leonard SR, Roy L, Nikaidoh H. The aortic translocation (Nikaidoh) procedure: midterm results superior to the Rastelli procedure. J Thorac Cardiovasc Surg. 2007;133:461-9.

22. Hu SS, Li SJ, Wang X, Wang L, Xiong H, Li L, et al. Pulmonary and aortic root translocation in the management of transposition of the great arteries with ventricular septal defect and left ventricular outflow tract obstruction. J Thorac Cardiovasc Surg. 2007;133:1090-2.

23. Hu SS, Li SJ, Liu ZG, Li Y, Wang L. The double-root translocation technique. Oper Tech Thorac Cardiovasc Surg. 2009;14:35-44

24. Park CS, Seo DM, Park JJ, Kim YH, Park IS. The significance of pulmonary annulus size in the surgical management of transposition of the great arteries with ventricular septal defect and pulmonary stenosis. $J$ Thorac Cardiovasc Surg. 2010;139:135-8. 